\title{
Clinical impact of upper gastrointestinal endoscopy in critically ill patients with suspected bleeding
}

Sylvain Jean-Baptiste ${ }^{1}$, Jonathan Messika ${ }^{1,2,3+} \mathbb{D}$, David Hajage ${ }^{4,5,6,7+}$, Stéphane Gaudry ${ }^{1,6,7}$, Julie Barbieri ${ }^{8}$, Henri Duboc ${ }^{9}$, Didier Dreyfuss ${ }^{1,2,3}$, Benoit Coffin ${ }^{8,9}$ and Jean-Damien Ricard ${ }^{1,2,3^{*}}$

\begin{abstract}
Background and Aims: Upper gastrointestinal endoscopies' (UGE) profitability is undisputable in patients admitted for an overt upper digestive tract bleeding. In critically ill subjects admitted for other causes, its performances have scarcely been investigated despite its broad use. We sought to question the performance of bedside UGE in intensive care unit (ICU) patients, admitted for another reason than overt bleeding.

Methods: This was a six-year (January 2007-December 2012) retrospective observational study of all UGE performed in a medico-surgical ICU. Exclusion of those performed: in patients admitted for a patent upper digestive bleeding; for a second-look gastroscopy of a known lesion; as a planned interventional procedure. Main demographic and clinical data were recorded; UGE indication and profitability were rated according to its findings and therapeutic impact. Operative values of the indications of UGE were calculated. This study received approval from the Ethics Committee of the French Society of Intensive Care ( $\left.n^{\circ} 12-363\right)$.
\end{abstract}

Results: Eighty-four patients ( $74 \%$ male, mean age $61 \pm 14$ years) underwent a diagnostic UGE, all for a suspected upper digestive tract bleeding. The main symptoms justifying the procedure were anemia (52\%), digestive bleeding (27\%), vomiting (15\%), hemodynamic instability (3\%) and hyperuremia (3\%). The profitability of UGE was rated as major $(n=5 ; 5.8 \%)$; minor $(n=34 ; 40.5 \%)$; or null $(n=45 ; 53.6 \%)$.

Conclusions: When ICU admission is not warranted by a digestive bleeding, UGE has limited diagnostic and therapeutic interest, despite being often performed.

Keywords: Upper gastrointestinal endoscopy, Intensive care unit, Profitability

\section{Background}

Bedside upper gastrointestinal endoscopy (UGE) is a procedure frequently performed in critically ill patients admitted to the intensive care unit (ICU). It has both a diagnostic (macroscopic examination of the lesions and biopsy sampling) and a therapeutic role (hemostatic vasoconstrictor injection, clipping, ligation of esophageal varices, etc.).

\footnotetext{
*Correspondence: jean-damien.ricard@aphp.fr

${ }^{\dagger}$ Jonathan Messika and David Hajage have contributed equally to this work

${ }^{1}$ Medico-Surgical Intensive Care Unit, AP-HP, Hôpital Louis Mourier, 178 rue des Renouillers, 92700 Colombes, France

Full list of author information is available at the end of the article
}

Its performance is well demonstrated for the management of patients admitted for upper digestive tract bleeding [1-9]. Nevertheless, apart from this specific context, a bedside UGE is also frequently performed in patients admitted for another reason, in which an upper digestive bleeding suspicion is raised during the course of ICU stay. The reasons for such suspicion might be the occurrence of exteriorized bleeding, an acute anemia, an hemodynamic instability or an hyperuremia without renal failure [10-12].

The performance and added value of UGE in this indication are much more debated [10, 13-16]. Indeed, critically ill patients often present with complex medical situations, many reasons to account for these signs (such 
as bleeding from another site, inflammatory anemia, sepsis and acute kidney injury). Furthermore, the discovery of a mucosal lesion might not require any endoscopic nor pharmacological treatment (gastritis, esophagitis, nasogastric tube-associated ulcerations) $[17,18]$ and hypothetic benefits of this procedure must be weighed against its inherent costs and risks [19]. We therefore questioned the performance of a bedside UGE in critically ill patients, admitted for another reason than upper digestive bleeding in the ICU. Our hypothesis was that a majority of procedures, performed in a general ICU population to confirm or exclude a GI bleeding, would only find nonspecific, ICU-associated lesions that would not significantly influence the patients' management.

\section{Patients and methods}

We conducted a retrospective, monocenter study, in a single teaching-based, 12-bed medico-surgical ICU, of all UGE performed between January 2007 and December 2012. The Ethics Committee of the French Society of Intensive Care (SRLF) approved the study ( $\left.\mathrm{n}^{\circ} 12-363\right)$. An informed consent was waived due to the retrospective design of the study.

All the patients who underwent a gastroscopy were identified through the endoscopy unit's database, in which all UGEs performed in our institution are registered. All the patients who had an UGE performed during their ICU stay were included, and their whole medical records were analyzed. Excluded patients were those admitted for a patent upper digestive bleeding or those who underwent a second-look gastroscopy of a known lesion or for a planned interventional procedure (such as a gastric tube or esophageal prosthesis placement). When a patient underwent several procedures, only the first one was taken into account.

Data collected were age, gender, the reason for ICU admission, the Sequential Organ Failure Assessment (SOFA) score [20] at ICU admission and the number of organ failures according to the individual organ score of the SOFA score [20]. We also recorded the symptoms and conditions that motivated the UGE, its findings and the subsequent procedures performed if any. Vital status at ICU discharge was also recorded.

UGE was performed by a gastroenterologist (in most cases by a senior physician and in rare instances, by a trainee under a senior's supervision) with standard Fuji video gastroscope. It was performed under general anesthesia with orotracheal intubation or under sedation in patients with no previous intubation. If gastric hemorrhage was suspected, a $2.5 \mathrm{mg} / \mathrm{kg}$ IV infusion of erythromycin was performed 30-60 min before endoscopy.

For each UGE, its profitability was rated. It was considered as "major" if it allowed a hemostatic procedure or the diagnosis of a cancer; "minor" if it allowed a diagnosis of a peptic disorder, which could be pharmacologically treated; or "null" if it was normal or if the findings had no therapeutic consequence.

Continuous data are presented as mean and standard deviation unless otherwise indicated. Dichotomous data are presented as number and percentage. For each reason motivating the UGE, we calculated the operative values (sensibility, specificity, positive and negative predictive value) associated with a major or minor profitability of the UGE. The analyses were performed with $\mathrm{R}$ version 3.2.0.

\section{Results}

Patient demographics and characteristics

Patients' flowchart is shown in Fig. 1, and patients' characteristics are summarized in Table 1. Among 3352 ICU admissions, 84 patients (74\% male, mean age $61 \pm 14$ years) had not been admitted for upper digestive bleeding and underwent a diagnostic UGE during their ICU stay, after a mean of $13 \pm 16$ days of ICU admission. Main reason for ICU admission was sepsis (81\%), $38 \%$ were surgical patients, and $7 \%$ were admitted in ICU following a gastroesophageal surgery. A multiorgan failure was present in most of them, as $92 \%$ received invasive mechanical ventilation and $62 \%$ had vasopressors. The mean SOFA score at admission was $7.7 \pm 3.7$. In our cohort, ICU mortality was $29 \%$.

\section{UGE indication}

The reasons for performing the UGE are shown in Table 2. In every case, an upper bleeding was suspected.

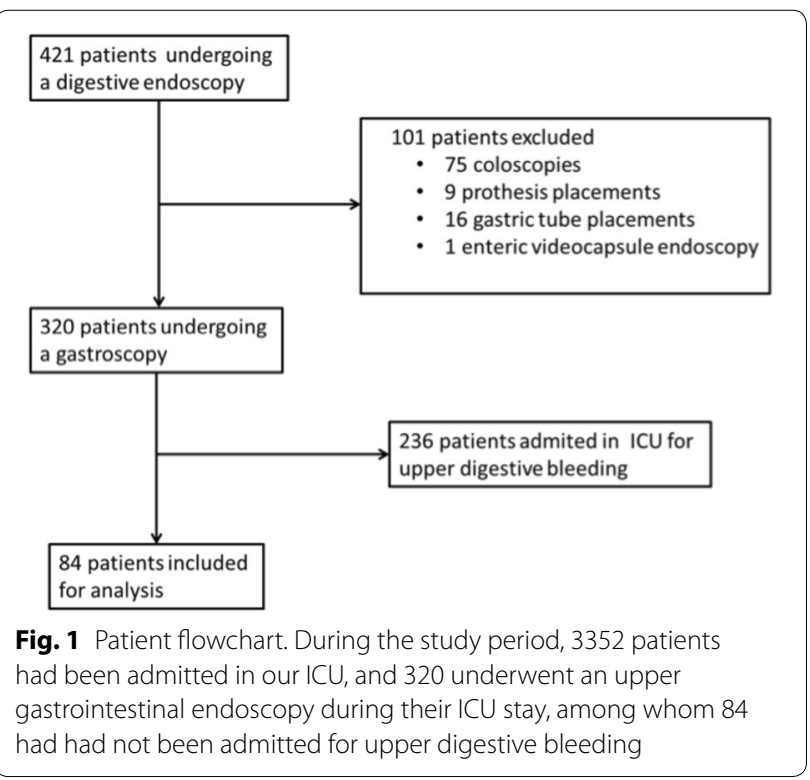


Table 1 Characteristics of the 84 critically ill patients undergoing a bedside upper gastrointestinal endoscopy

$\begin{array}{ll}\text { Patients' characteristics. } n=84 & \\ \text { Age (years) } & 61.7 \pm 14 \\ \text { Male sex } & 62(74 \%) \\ \text { Medical patients } & 52(62 \%) \\ \text { Surgical patients } & 32(38 \%) \\ \text { Esogastric surgery } & 6(7 \%) \\ \text { SOFA score } & 7.7 \pm 3.7 \\ \text { Mechanical ventilation } & 77(92 \%) \\ \text { Vasopressor } & 52(62 \%) \\ \text { Acute kidney injury } & 50(60 \%) \\ \text { Sepsis } & 68(81 \%)\end{array}$

Data are expressed as mean $\pm S D$, or $n(\%)$; SOFA: Sequential Organ Failure Assessment SOFA scores can range from 0 (no organ failure) to 24 (most severe level of multiorgan failure)

Table 2 Reasons for performing the upper gastrointestinal endoscopy in the 84 critically ill patients

\begin{tabular}{ll}
\hline Acute anemia & $50(60 \%)$ \\
Digestive bleeding & $26(31 \%)$ \\
Vomiting & $14(17 \%)$ \\
Hemodynamic instability & $3(4 \%)$ \\
Hyperuremia & $3(4 \%)$ \\
\hline
\end{tabular}

One patient could have various reasons for performing the upper gastrointestinal endoscopy. Data are presented in $n(\%)$

Table 3 Findings of the 84 upper gastrointestinal endoscopy performed

\begin{tabular}{ll}
\hline Normal & $25(30 \%)$ \\
Esophagitis or gastritis & $14(17 \%)$ \\
Nasogastric tube erosion & $18(21 \%)$ \\
Peptic ulcer & $13(15 \%)$ \\
Esophagogastric varices & $4(5 \%)$ \\
Amyloidosis & $1(1 \%)$ \\
Esophageal candidosis & $7(8 \%)$ \\
Cancer & $2(2 \%)$ \\
\hline
\end{tabular}

Data are presented as $n(\%)$

The main symptoms justifying the procedure according to the attending physician were acute anemia (52\%), digestive bleeding (27\%), vomiting (15\%), hemodynamic instability (3\%) and hyperuremia (3\%).

\section{UGE findings}

The findings of the UGE are shown in Table 3. It was considered normal in $30 \%$ of those $(n=25)$. Among abnormal findings, the most frequent were nasogastric tube erosions $(n=18)$, peptic gastritis or esophagitis $(n=14)$, peptic gastric ulcer $(n=13)$, esophageal candidiasis $(n=7)$, esogastric varices $(n=4)$. According to our prespecified classification, we considered that 5 UGE had a major profitability (5.8\%) and $34(40.5 \%)$ had a minor profitability, and for 45 (53.6\%), this profitability was null.

\section{Diagnostic and predictive value}

Sensibility, specificity, positive and negative predictive value (PPV and NPV) of the symptoms and conditions that motivated the procedures are shown in Table 4 . Hemodynamic instability had a PPV of $100 \%$ but was present in only 3 patients and always associated with at least another sign (drop in hemoglobin in 3 and overt digestive bleeding in 2). The second best PPV was $66.7 \%$ for hyperuremia. It has to be noted that that acute anemia and digestive bleeding have not a high PPV (61.5 and $48 \%$, respectively).

\section{Discussion}

In our 6-year retrospective review of all UGE performed in a single medico-surgical ICU, we showed that although regularly performed, UGE for critically ill patients initially hospitalized for another reason than upper digestive bleeding but for whom the question of upper digestive bleeding is raised during their ICU stay has limited diagnostic and therapeutic interest during ICU stay.

This is, to our knowledge, the largest study assessing the profitability of this procedure in this specific patient population.

In this population of non-selected ICU patients, with the suspicion of ICU-acquired upper digestive bleeding, we found that UGE was strictly normal in one third of procedures. When performed in patients in whom gastrointestinal bleeding was not suspected, Ovenden et al. reported that UGE was normal in two-thirds of procedures [18]. The vast majority of abnormal findings we observed $(n=45 ; 76 \%)$ were either peptic lesions (i.e., ulcer or esophagitis/gastritis) or nasogastric tube-associated erosions. Similar lesions were reported by Ovenden et al. In this series of 74 patients who underwent an UGE, a pathological finding was found in $34 \%$ of the subjects, either gastritis/erosions in $14 \%$, nasogastric tube trauma in 8 (11\%), esophagitis in $4(5 \%)$ and non-bleeding duodenal ulceration in 3 (4\%) [18].

In our series, an active bleeding was only retrieved in three of the 13 peptic ulcers at the time of the UGE, therefore requiring an instrumental hemostasis procedure (submucosal adrenaline injection and clip application). Nasogastric tube erosions were always considered incidental findings that could not be held responsible for the symptoms and that did not change the patients' management. The other lesions found were mostly incidental that did not account for any significant digestive 
Table 4 Diagnostic and predictive values of upper gastrointestinal endoscopy in critically ill subjects

\begin{tabular}{lcccl}
\hline & Sensibility & Specificity & PPV & NPV \\
\hline Esogastric surgery & 7.7 & 93.3 & 50.0 & 53.8 \\
Acute kidney injury & 46.2 & 28.9 & 36.0 & 38.2 \\
Coagulopathy & 20.5 & 80.0 & 47.1 & 53.7 \\
Sepsis & 79.5 & 17.8 & 45.6 & 50 \\
Shock & 61.5 & 37.8 & 46.2 & 53.1 \\
Mechanical ventilation & 87.2 & 4.4 & 44.2 & 28.6 \\
Cirrhosis & 10.3 & 86.7 & 40.0 & 52.7 \\
History of ulcer & 7.7 & 93.3 & 50.0 & 53.8 \\
Acute anemia & 61.5 & 42.2 & 48.0 & 55.9 \\
Hyperuremia & 5.1 & 97.8 & 66.7 & 54.3 \\
Hemodynamic instability & 7.7 & 100 & 100 & 55.6 \\
Digestive bleeding & 25.6 & 64.4 & 38.5 & 50.0 \\
Vomiting & 15.4 & 82.2 & 42.9 & 52.9 \\
\hline
\end{tabular}

Data are presented as \%

$P P V$ positive predictive value, $N P V$ negative predictive value

bleeding. We can infer that not only the suspicion of active bleeding is very infrequent, but also, when suspected its occurrence, is very rare.

These results are of importance since UGE is a costly and time-consuming procedure, for both ICU and endoscopy teams, that can cause significant morbidity if performed unduly [21]. Its poor performance can probably be explained by the large prescription of prophylactic proton pump inhibitors in our unit for the patients that present several risk factors for the socalled stress related mucosal disease. Although prevention with prophylactic proton pump inhibitor has been showed to be safe $[4,5,22]$, its use is still being challenged [23-25]. Our study population was composed of patients presenting multiple organ failure so the results cannot be explained by a lack of severity of the patients, as attested by the high SOFA score.

Whereas previous reports focused on UGE performed in the ICU for overt gastrointestinal bleeding $[7,16]$, Plaisier et al. [15] described the indications and results of 411 gastroscopies performed in 4 ICUs of a single Dutch hospital. Unlike our series, most patients were admitted for a gastrointestinal hemorrhage. Nevertheless, in patients undergoing the UGE for another reason, esophagitis, gastritis and gastric ulcer were the most frequent coincidental findings, as in our series. Of interest, in this setting, UGE was also widely used (in $35 \%$ of cases) for the placement of feeding tubes, which was a very uncommon indication in our series.

The operative values of the symptoms and conditions that justified performing the UGE are disappointingly poor. None of them was found to be discriminating enough to be useful, alone, in clinical practice.

It is interesting to note that we observed an unexpectedly high number of esophageal candidiasis. None of these patients had an HIV infection or hematologic malignancy, and this diagnosis was never evoked before the UGE was performed. Although this was considered an incidental finding and an unlikely cause of digestive bleeding, all of them were treated by fluconazole [26, 27]. Risk factors and incidence of esophageal candidiasis in ICU patients are poorly studied [27], and our work raises the concern that this condition might be underdiagnosed and undertreated.

Our study holds several limitations. First, the retrospective design does not allow to drawing any definitive conclusion concerning the efficacy of upper digestive endoscopy in ICU patients suspected of ICU-acquired upper digestive bleeding. Nevertheless, the review of the whole charts and the gastroscopy report of the patients included enables to retrace the exact motives of the endoscopy.

Second, although we do acknowledge the number of patients is small $(n=84)$ with regard to the number of subjects admitted in our ICU during the study period $(n=3352)$, we can explain it with our policy of proton pump inhibitor prescription in subjects with a risk factor for digestive bleeding, and of active enteral nutrition of all patients for whom the digestive tract can be used. Third, our data reflect the experience of a single center, and the decision to perform the endoscopies or the hemostatic procedures were left to the attending intensivist and endoscopist and we cannot rule out that the results might have been different in another patient population treated by another medical team and our findings may not be generalized. Nevertheless, the decision to perform a gastroscopy is generally taken within the whole ICU medical team, with habits that did not change during the study period, and hemostatic procedures were performed according to the standard guidelines.

These limitations taken into account, we propose that UGE is of very limited use in ICU patients suspected of ICU-acquired upper digestive bleeding. The low yield of UGE in our center suggests that these patients can be managed with a watchful waiting when hemodynamically stable.

\section{Conclusions}

Bedside UGE has very poor diagnostic and therapeutic performances when performed in a population of intensive care patient suspected of ICU-acquired upper digestive bleeding. These results should be confirmed by a prospective multicenter observational cohort. 


\section{Abbreviations}

ICU: Intensive care unit; SOFA: Sequential Organ Failure Assessment; UGE: upper gastrointestinal endoscopy.

\section{Authors' contributions}

SJ-B, JM and J-DR contributed to study concept and design; SJ-B, SG, JB and HD contributed to acquisition of data; SJ-B, JM, DH and J-DR contributed to analysis and interpretation of data; SJ-B, JM, DH and J-DR contributed to drafting of the manuscript; SG, HD, DD, BC and J-DR contributed to critical revision of the manuscript for important intellectual content; $\mathrm{DH}$ contributed to statistical analysis; SG, JB, HD and BC contributed to administrative, technical or material support; and J-DR contributed to study supervision. All authors read and approved the final manuscript.

\section{Author details}

1 Medico-Surgical Intensive Care Unit, AP-HP, Hôpital Louis Mourier, 178 rue des Renouillers, 92700 Colombes, France. ${ }^{2}$ IAME, UMR 1137, INSERM, 75018 Paris, France. ${ }^{3}$ IAME, UMR 1137, Univ Paris Diderot, Sorbonne Paris Cité, 75018 Paris, France. ${ }^{4}$ Département de Biostatistiques, Santé Publique et Information Médicale, AP-HP, Hôpital Pitié-Salpêtrière, 75013 Paris, France. ${ }^{5}$ Univ Pierre et Marie Curie, Sorbonne Universités, 75013 Paris, France. ${ }^{6}$ ECEVE, U1123, CIC-EC 1425, INSERM, 75010 Paris, France. ${ }^{7}$ ECEVE, UMRS 1123, Univ Paris Diderot, Sorbonne Paris Cité, 75010 Paris, France. ${ }^{8}$ Gastroenterology Unit, AP-HP, Hôpital Louis Mourier, 178 rue des Renouillers, 92700 Colombes, France ${ }^{9}$ Univ Paris Diderot, Sorbonne Paris Cité, 75018 Paris, France.

\section{Competing interests}

The authors declare that they have no competing interests.

\section{Ethics approval and consent to participate}

The Ethics Committee of the French Society of Intensive Care (SRLF) approved the study ( $\left.n^{\circ} 12-363\right)$. An informed consent was waived.

\section{Funding}

None.

\section{Publisher's Note}

Springer Nature remains neutral with regard to jurisdictional claims in published maps and institutional affiliations.

Received: 19 January 2018 Accepted: 28 June 2018

Published online: 04 July 2018

\section{References}

1. Lau JYW, Barkun A, Fan D, Kuipers EJ, Yang Y, Chan FKL. Challenges in the management of acute peptic ulcer bleeding. Lancet Lond Engl. 2013;381:2033-43.

2. Gralnek IM, Barkun AN, Bardou M. Management of acute bleeding from a peptic ulcer. N Engl J Med. 2008;359:928-37. http://www.nejm.org/doi/ abs/10.1056/NEJMra0706113. Cited 29 March 2017.

3. Cook DJ, Fuller HD, Guyatt GH, Marshall JC, Leasa D, Hall R, et al. Risk factors for gastrointestinal bleeding in critically ill patients. N Engl J Med. 1994;330:377-81. http://www.nejm.org/doi/abs/10.1056/NEJM199402 103300601. Cited 29 March 2017.

4. Barkun AN, Bardou M, Pham CQD, Martel M. Proton pump inhibitors vs. histamine 2 receptor antagonists for stress-related mucosal bleeding prophylaxis in critically ill patients: a meta-analysis. Am J Gastroenterol. 2012;107:507-20 (quiz 521)

5. Alhazzani W, Alenezi F, Jaeschke RZ, Moayyedi P, Cook DJ. Proton pump inhibitors versus histamine 2 receptor antagonists for stress ulcer prophylaxis in critically ill patients: a systematic review and meta-analysis. Crit Care Med. 2013;41:693-705

6. Spiegel BM, Vakil NB, Ofman JJ. Endoscopy for acute nonvariceal upper gastrointestinal tract hemorrhage: is sooner better? A systematic review. Arch Intern Med. 2001;161:1393-404.

7. Lin HJ, Wang K, Perng CL, Chua RT, Lee FY, Lee CH, et al. Early or delayed endoscopy for patients with peptic ulcer bleeding. A prospective randomized study. J Clin Gastroenterol. 1996;22:267-71.

8. LuY, Loffroy R, Lau JYW, Barkun A. Multidisciplinary management strategies for acute non-variceal upper gastrointestinal bleeding. Br J Surg. 2014;101:e34-50.
9. Barkun AN, Bardou M, Kuipers EJ, Sung J, Hunt RH, Martel M, et al. International consensus recommendations on the management of patients with nonvariceal upper gastrointestinal bleeding. Ann Intern Med. 2010;152:101-13.

10. Richards RJ, Donica MB, Grayer D. Can the blood urea nitrogen/creatinine ratio distinguish upper from lower gastrointestinal bleeding? J Clin Gastroenterol. 1990;12:500-4.

11. Mortensen PB, Nøhr M, Møller-Petersen JF, Balslev I. The diagnostic value of serum urea/creatinine ratio in distinguishing between upper and lower gastrointestinal bleeding. A prospective study. Dan Med Bull. 1994;41:237-40.

12. Witting MD, Magder $L$, Heins AE, Mattu A, Granja CA, Baumgarten M. ED predictors of upper gastrointestinal tract bleeding in patients without hematemesis. Am J Emerg Med. 2006;24:280-5. http://linkinghub.elsevier. com/retrieve/pii/S0735675705004274. Cited 29 March 2017.

13. Lee Y-C, Wang H-P, Wu M-S, Yang C-S, Chang Y-T, Lin J-T. Urgent bedside endoscopy for clinically significant upper gastrointestinal hemorrhage after admission to the intensive care unit. Intensive Care Med. 2003;29:1723-8.

14. Zaltman C, Souza HSP de, Castro MEC, Sobral M de FS, Dias PCP, Lemos V. Upper gastrointestinal bleeding in a Brazilian hospital: a retrospective study of endoscopic records. Arq Gastroenterol. 2002;39:74-80.

15. Plaisier PW, van Buuren HR, Bruining HA. Upper gastrointestinal endoscopy at four intensive care units in one hospital: frequency and indication. Eur J Gastroenterol Hepatol. 1998;10:997-1000.

16. Lewis JD, Shin EJ, Metz DC. Characterization of gastrointestinal bleeding in severely ill hospitalized patients. Crit Care Med. 2000;28:46-50.

17. Hayden SJ, Albert TJ, Watkins TR, Swenson ER. Anemia in critical illness: insights into etiology, consequences, and management. Am J Respir Crit Care Med. 2012;185:1049-57.

18. Ovenden C, Plummer MP, Selvanderan S, Donaldson TA, Nguyen NQ, Weinel LM, et al. Occult upper gastrointestinal mucosal abnormalities in critically ill patients. Acta Anaesthesiol Scand. 2017;61:216-23. http://doi.wiley .com/10.1111/aas.12844. Cited 9 June 2018.

19. Tam WY, Bertholini D. Tension pneumoperitoneum, pneumomediastinum, subcutaneous emphysema and cardiorespiratory collapse following gastroscopy. Anaesth Intensive Care. 2007:35:307-9.

20. Vincent JL, Moreno R, Takala J, Willatts S, De Mendonca A, Bruining H, et al. The SOFA (Sepsis-related Organ Failure Assessment) score to describe organ dysfunction/failure. On behalf of the Working Group on Sepsis-Related Problems of the European Society of Intensive Care Medicine. Intensive Care Med. 1996;22:707-10. http://www.ncbi.nlm.nih.gov/entrez/query .fcgi?cmd=Retrieve\&db=PubMed\&dopt=Citation\&list_uids $=8844239$.

21. Rehman A, Iscimen R, Yilmaz M, Khan H, Belsher J, Gomez JF, et al. Prophylactic endotracheal intubation in critically ill patients undergoing endoscopy for upper Gl hemorrhage. Gastrointest Endosc. 2009;69:e55-9.

22. Selvanderan SP, Summers MJ, Finnis ME, Plummer MP, Ali Abdelhamid Y, Anderson MB, et al. Pantoprazole or placebo for stress ulcer prophylaxis (POP-UP): randomized double-blind exploratory study*. Crit Care Med. 2016;44:1842-50. http://Insights.ovid.com/crossref?an=00003246-20161 0000-00006. Cited 1 June 2018.

23. Krag M, Perner A, Wetterslev J, Wise MP, Borthwick M, Bendel S, et al. Stress ulcer prophylaxis with a proton pump inhibitor versus placebo in critically ill patients (SUP-ICU trial): study protocol for a randomised controlled trial. Trials. 2016:17:205

24. Alhazzani W, Guyatt G, Alshahrani M, Deane AM, Marshall JC, Hall R, et al. Withholding pantoprazole for stress ulcer prophylaxis in critically ill patients: a pilot randomized clinical trial and meta-analysis*. Crit Care Med. 2017:45:1121-9. http://Insights.ovid.com/crossref?an=00003246-20170 7000-00003. Cited 1 June 2018.

25. El-Kersh K, Jalil B, McClave SA, Cavallazzi R, Guardiola J, Guilkey K, et al. Enteral nutrition as stress ulcer prophylaxis in critically ill patients: a randomized controlled exploratory study. J Crit Care. 2018;43:108-13. http://linki nghub.elsevier.com/retrieve/pii/S0883944117305294. Cited 1 June 2018.

26. Cuenca-Estrella M, Verweij PE, Arendrup MC, Arikan-Akdagli S, Bille J, Donnelly JP, et al. ESCMID* quideline for the diagnosis and management of Candida diseases 2012: diagnostic procedures. Clin Microbiol Infect Off Publ Eur Soc Clin Microbiol Infect Dis. 2012;18(Suppl 7):9-18.

27. Weerasuriya N, Snape J. Oesophageal candidiasis in elderly patients: risk factors, prevention and management. Drugs Aging. 2008;25:119-30. 